\title{
Role of oral teriflunomide in the management of multiple sclerosis
}

\author{
This article was published in the following Dove Press journal: \\ Neuropsychiatric Disease and Treatment \\ 19 April 2013 \\ Number of times this article has been viewed
}

\author{
Radu Tanasescu' ${ }^{1,2}$ \\ Nikos Evangelou' \\ Cris S Constantinescu' \\ 'Academic Division of Clinical \\ Neurology, University of Nottingham, \\ Nottingham, UK; ; ${ }^{2}$ epartment of \\ Neurology, Colentina Hospital, Carol \\ Davila University of Medicine and \\ Pharmacy, Bucharest, Romania
}

\begin{abstract}
The landscape of the treatment of relapsing-remitting multiple sclerosis is changing fast. Several oral treatments have shown benefit and generate much interest because of the convenience of their administration. Two oral compounds, fingolimod and teriflunomide, have been approved in relapsing-remitting multiple sclerosis, while others have completed Phase III trials and are awaiting review for registration. Teriflunomide is a pyrimidine synthesis inhibitor with selective immunomodulatory and immunosuppressive properties that have shown consistent efficacy in clinical trials, and a good safety profile. This paper provides an overview of the mechanisms of action and efficacy and safety results from clinical trials with this drug. The role of teriflunomide in the treatment of relapsing-remitting multiple sclerosis is discussed.
\end{abstract}

Keywords: teriflunomide, multiple sclerosis, oral drugs, clinical trials

\section{Introduction}

Multiple sclerosis (MS) is a chronic, immune-mediated disease of the central nervous system. Pathologic hallmarks of MS lesions are inflammation, demyelination, axonal degeneration, neuronal loss, and gliosis. ${ }^{1}$

MS initially presents in most patients as a relapsing-remitting condition (RRMS), but the majority of RRMS individuals later develop a secondary progressive course. ${ }^{2}$ In fewer cases, the disease progresses from the beginning without relapses (primary progressive MS) or with rare superimposed relapses (progressive relapsing MS). ${ }^{3}$

The clinical signs in MS can occur in isolation or in combination and can include motor and sensory deficits, partial or complete visual loss, diplopia, impaired coordination, and gait dysfunction. The diagnosis specifically integrates magnetic resonance imaging (MRI) with clinical attacks and paraclinical methods, and implies the dissemination of inflammatory activity in time and in space. ${ }^{4}$

Immunomodulatory drugs used to treat MS decrease the clinical relapse rate and accompanying inflammation within the central nervous system. Initially approved therapies were all injectable (either subcutaneous or parenteral) and include interferon- $\beta$ (IFN $\beta$ ), glatiramer acetate (GA), natalizumab, and mitoxantrone. ${ }^{5}$

The oral drugs emerged from the unmet needs for new mechanistic therapies tackling inflammation and disability progression, and for easy and convenient administration regimens. The latter would translate into an ease of the burden of long-term self-administered injections or recurrent intravenous infusions, thus improving quality of life and increasing adherence to therapy. ${ }^{6}$

Currently, five oral therapies have completed Phase III clinical trials (fingolimod, laquinimod, dimethyl fumarate, teriflunomide, and cladribine) and have been or are
Correspondence: Radu Tanasescu Academic Division of Clinical Neurology, C Floor, South Block, Queen's Medical Center, University of Nottingham, Nottingham NG7 2UH, UK

Tel +440 I I5 823 I4433

Fax +440II5 9709738

Email radu.tanasescu@nottingham.ac.uk 
currently in the process of being evaluated by medical agencies in the US and Europe..$^{7-17}$

In this review, the role of teriflunomide (Aubagio ${ }^{\circledR}$; Genzyme Corporation, Cambridge, MA, USA) in the management of MS is discussed. Efficacy data arising from clinical studies will be contrasted with known and potential risks in an attempt to place the drug within the new therapeutic armamentarium of MS. Currently, Aubagio is marketed in the US and Australia and is under review by the European Medicines Agency and other regulatory authorities.

\section{Teriflunomide - mechanisms of action and pharmacology}

Teriflunomide is the active metabolite of leflunomide, a drug approved for use in patients with rheumatoid arthritis since 1998 (Figure 1). ${ }^{18}$ Oral leflunomide is almost entirely converted into teriflunomide, thus data on leflunomide could provide useful information on teriflunomide pharmacology. ${ }^{19}$ Teriflunomide has both antiproliferative and anti-inflammatory activities exerted through several mechanisms, the main one being inhibition of pyrimidine synthesis, and also inhibition of protein tyrosine kinases (Table 1). Teriflunomide acts as a reversible inhibitor of a mitochondrial membrane protein essential for pyrimidine synthesis (dihydroorotate dehydrogenase; DHODH) (Figure 2). ${ }^{20} \mathrm{By}$ blocking de novo pyrimidine synthesis, teriflunomide inhibits proliferation of autoreactive B-cells and T-cells by cell cycle arrest in the G1 phase. However, cellular salvage pathways for proliferation exist and allow slowly dividing cell lines such as hematopoietic cells, memory cells, and gastrointestinal lining cells to sustain ongoing pyrimidine metabolism and to survive. Consequently, the potential for significant cytopenia

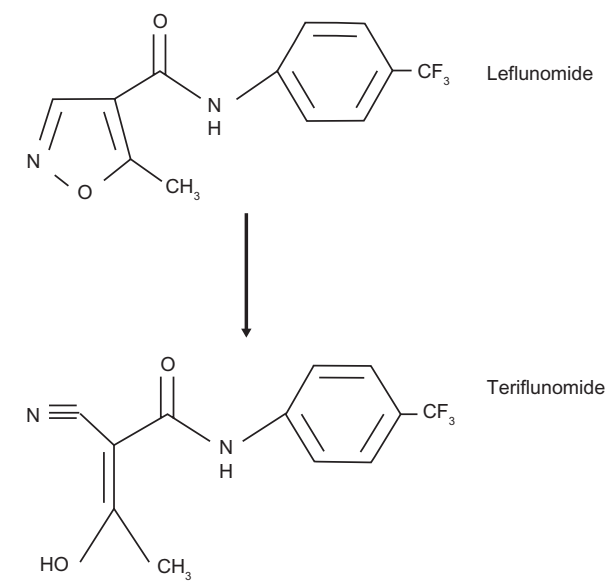

Figure I Chemical structure of teriflunomide and leflunomide.

Reprinted from Tallantyre et al. The International MS Journal. 2008;15(2):62-68 with permission from Cambridge Medical Publications (CMP). ${ }^{20}$
Table I Actions of teriflunomide accounting for the effects on the immune cells

Inhibition of dihydroorotate dehydrogenase

Inhibition of protein tyrosine kinase

Inhibition of cyclooxygenase-2

Downregulation of inducible nitric oxide synthase

is reduced..$^{20}$ Apart from inhibiting nucleic acids synthesis, the reduced availability of pyrimidines could also induce impaired generation of lipid messengers and malfunction of cell surface molecules, with further immunomodulatory consequences. $^{21}$

Very recently it was suggested that teriflunomide differentially modulates the proliferative capacity of antigen specific T-cell clones. ${ }^{22}$ Teriflunomide more efficiently blocks the expansion of vigorously proliferating high avidity T-cell clones (that are more dependent on the de novo pyrimidine synthesis pathway) than low affinity ones. Thus, while in parallel, this will allow normal T-cell homeostasis and responsiveness to certain antigens. Indeed, treatment with teriflunomide does not impede appropriate immune responses to seasonal influenza vaccination, suggesting that the memory response to (at least) influenza vaccine is not significantly affected by the drug. ${ }^{23}$ However, since the induced degree of lymphopenia is small, it only partially accounts for global effects of teriflunomide. ${ }^{24}$ Moreover, the effects of teriflunomide on lymphocyte migration, cytokine production, and surface molecule expression persist despite exogenous pyrimidine administration. ${ }^{25}$ Based on in vitro data, it has been suggested that the inhibition of protein tyrosine kinase (PTK) activity might be another mechanism which mediates the immune effects of teriflunomide, although doubts were

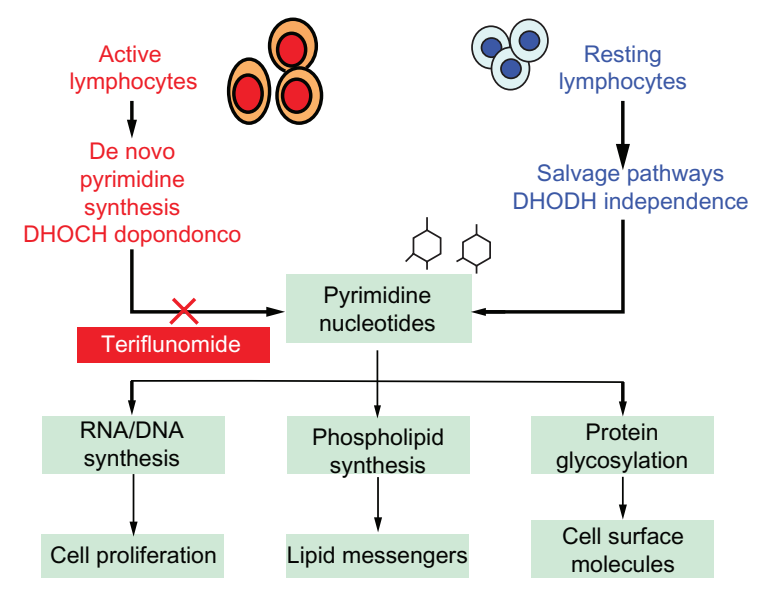

Figure 2 Principal mechanisms of teriflunomide.

Reprinted from Tallantyre et al. The International MS Journal. 2008;15(2):62-68 with permission from Cambridge Medical Publications (CMP). ${ }^{20}$ 
raised about the very high concentrations required in vivo in mice for this activity to take place. However, taking into account differences between human and rodent cell lines, the immune effects of teriflunomide via PTK inhibition might be clinically relevant at therapeutic concentrations in humans. ${ }^{26}$

Supporting PTK inhibition as a mechanism of action for the drug, it was demonstrated in animal models that teriflunomide may inhibit epithelial growth factor receptor tyrosine kinases p56, and p59, which are members of the Src-PTK family, and Janus tyrosine kinases jak1 and jak3. ${ }^{27-31}$ This would reduce T-cell proliferation and production of IFN- $\gamma$, interleukin-2, and granzyme B, immunoglobulin G1 production by B-cells, and inhibit calcium mobilization and nuclear factor- $\kappa \mathrm{B} \cdot{ }^{29,32}$

Overall, teriflunomide exerts immunomodulatory effects by influencing the function of B-cells and T-cells, and interfering with the innate immunity. ${ }^{33}$ Teriflunomide has the potential to induce a switch of cytokine profiles from Th1 (proinflammatory) to Th2 (anti-inflammatory) as shown in animal and human studies. ${ }^{21,34}$ Stimulation of T-cells in vitro in the presence of leflunomide led to an increase in anti-inflammatory molecules interleukin-1 receptor antagonist and tissue inhibitor of metalloproteinase- $1 .{ }^{35}$ By blocking integrin function at different stages of T-cell activation, teriflunomide decreases the ability of antigen-presenting cells to activate T-cells and stimulate T-cells to activate monocytes. ${ }^{21,26}$

Teriflunomide may affect T-cell migratory capability both in vitro and in vivo and modulate the interaction between T-cells and B-cells by inhibiting T-cell-dependent antibody production. ${ }^{26,33,36}$ In addition, teriflunomide may act via cyclooxygenase-2 inhibition and may downregulate inducible nitric oxide synthase activity in macrophages and astrocytes, although the clinical relevance of these effects may be limited. ${ }^{37-39}$ Also, it was recently shown that the drug may interfere via a DHODH-independent pathway with human monocyte-derived dendritic cell function, but without broadly impairing the capacity of dendritic cells to regulate adaptive immunity. ${ }^{40}$ Finally, teriflunomide may interfere via DHODH with innate immune system function by modulating the expression of adhesion molecules, migration, and adherence of neutrophils and macrophages, as well as controlling proliferation of myeloid progenitors or mast cell lines. ${ }^{41}$ In conclusion, although teriflunomide exerts its immunomodulatory effects through a variety of mechanisms and has the potential to impede T-cell activation in a multifaceted manner, DHODH inhibition remains its principal mechanism of action. ${ }^{42}$
Teriflunomide is an open ring malononitrile not related structurally to other immunosuppressive compounds and has a linear pharmacokinetics profile. ${ }^{36}$ Pharmacokinetics data from eleven studies on healthy volunteers and one study on patients with MS receiving teriflunomide shows an absolute oral bioavailability close to $100 \%$, with a median time to peak plasma concentration of 1-2 hours, delayed by food. ${ }^{43}$ The drug is cleared via adrenal and biliary routes with the participation of several cytochrome P450 (CYP) enzymes and $\mathrm{N}$-acetyltransferase. ${ }^{44}$

The drug is protein bound above $99 \%$ and has a plasma half-life of 15-18 days, having only limited penetration across the blood-brain barrier. $^{21}$ Teriflunomide weakly inhibits CYP3A and its pharmacokinetics profile is not influenced by coadministration with warfarin (a CYP2C9 substrate).$^{43}$ However, it can be expected that inducers of CYP3A will accelerate teriflunomide elimination, while teriflunomide will prolong the half-lives of compounds such as phenytoin, warfarin, or nonsteroidal anti-inflammatory drugs which are eliminated via CYP2C9. ${ }^{36,45}$ The clinical significance of most of those interactions is not known and needs further study. Recently, it was reported that repeated doses of teriflunomide had no effect on the pharmacokinetics of warfarin, indicating that teriflunomide is not an inhibitor or an inducer of CYP2C9. ${ }^{46}$ However, a $25 \%$ decrease in peak international normalized ratio was observed when teriflunomide was coadministered with warfarin, therefore international normalized ratio follow-up and close monitoring are recommended. ${ }^{46}$ Moreover, consideration should be given to the type or dose of oral contraceptives used in combination with teriflunomide, since the drug may increase exposure of ethinyl estradiol and levonorgestrel.

The drug is excreted through feces $(37.5 \%)$ and urine (22.6\%), has an elimination half-life of 10-12 days, and is not dependent on gender, age, or hepatic impairment. ${ }^{43}$ The elimination rate can be accelerated by administration of cholestyramine or activated charcoal, particularly useful in situations of overdose. ${ }^{43}$ Dialysis is not effective in removing teriflunomide, as recently shown in dialysis patients with rheumatoid arthritis. ${ }^{47}$

\section{Efficacy studies of teriflunomide in experimental models of MS}

Teriflunomide has been proven to be effective in experimental models of MS. This was shown initially for leflunomide, which appears to diminish the severity of adoptive transfer experimental allergic encephalomyelitis (EAE), a monophasic inflammatory demyelinating disease of the central nervous system induced by transfer of myelin basic protein-specific T-cell blasts. ${ }^{21,25}$ In experimental autoimmune 
neuritis, leflunomide decreased the titers of autoantibodies that developed against myelin proteins and reduced the intensity of clinical disease both in a prophylactic and therapeutic regimens. ${ }^{24}$ Some of these effects were independent of pyrimidine depletion. ${ }^{24}$ In an EAE model more closely reflecting the clinical course of human RRMS than acute monophasic EAE models (the Dark Agouti rat model of EAE, characterized by more progressive and sustained demyelination and associated axonal loss), various dosages of oral teriflunomide delayed disease onset and reduced neurological deficits in a dose-dependent manner and remained effective in different treatment scenarios. ${ }^{48}$ The prophylactic (ie, administered after the induction of EAE) and therapeutic effects of teriflunomide positively impacted electrophysiological assessments such as somatosensory evoked potential. ${ }^{48}$ Moreover, spinal cord histology showed that teriflunomide administered either therapeutically or as prophylaxis significantly led to reduction in axonal loss and demyelination by up to $90 \%$ and decreased the infiltrates of B-cells, T-cells, and macrophages. ${ }^{48}$ Moreover, teriflunomide $10 \mathrm{mg} / \mathrm{kg}$ administered after EAE induction had a positive impact on the number of surviving oligodendrocytes in the gracile fascicle. ${ }^{48}$ Finally, blood-brain barrier integrity assessed by MRI was spared for longer with doses of $3 \mathrm{mg} / \mathrm{kg}$ and completely preserved when higher doses $(10 \mathrm{mg} / \mathrm{kg})$ were used. ${ }^{48}$ These robust results from animal studies were convincing and encouraging for the initiation of clinical trials of teriflunomide in patients with MS.

\section{Clinical studies with teriflunomide}

Teriflunomide has different mechanisms of action compared to classical first-line disease-modifying therapies (DMTs). This creates the premise of its use in MS both as an add-on to approved DMTs or as a monotherapy. A comprehensive set of trials assessing its efficacy and safety using a range of clinical and MRI endpoints have been performed and have been previously summarized (Table 2 ). ${ }^{33}$ These are presented below.

A randomized, controlled Phase II study to determine safety and efficacy of teriflunomide monotherapy included 157 RRMS and 22 secondary progressive MS patients aged 18-65 years old with an Expanded Disability Status Scale (EDSS) score of less than six. Participants were included if they had had at least two relapses in the preceding 3 years and one clinical relapse during the last year. Subjects were randomized to three arms (placebo, teriflunomide $7 \mathrm{mg}$, or teriflunomide $14 \mathrm{mg}$ ). ${ }^{49}$ The trial included a 36 -week follow-up, with MRI every 6 weeks and clinical assessment every 12 weeks. The primary endpoint was the number of combined unique active lesions (CUALs), which included the number of new T2 lesions, enlarging T2 lesions, and those that were gadolinium-enhancing. The secondary endpoints included T2 lesion volume, relapse frequency, and EDSS change. A total of 160 patients completed the study. Results showed a significant reduction in CUAL numbers for both the $7 \mathrm{mg} /$ day and $14 \mathrm{mg}$ /day treatment groups versus placebo ( $-61 \% ; P<0.03$ and $P<0.01$, respectively); a lower burden of disease at 36 weeks compared with baseline in subjects receiving teriflunomide $14 \mathrm{mg} /$ day $(P<0.02)$; and a smaller proportion of patients with increase in disability in the $14 \mathrm{mg} /$ day treatment group $(P<0.04) .{ }^{49}$ The radiological effects were apparent at 6 weeks, reached statistical significance by 12 weeks, and were maintained throughout the study. There was a trend toward slower ARRs in the $14 \mathrm{mg}$ treatment group versus placebo (77\% versus $62 \%)$, which did not reach statistical significance $(P=0.098)$. However, the study was not sufficiently powered to analyze this secondary endpoint. Fewer patients in this group required steroids for disease exacerbations (14\% versus $23 \%$ in the placebo arm). ${ }^{49}$ Overall, treatment was well tolerated, with a similar number of adverse events (AEs) and serious AEs for all treatment groups.

The factors affecting CUAL decrease were confirmed in an open-label extension of the initial trial. ${ }^{50}$ Moreover, this extension confirmed that long-term treatment with teriflunomide does not lead to any decline in patient response, as reflected by MRI burden and clinical endpoints. ${ }^{51}$ This was observed in patients previously on placebo and switched to either $7 \mathrm{mg}$ /day or $14 \mathrm{mg} /$ day, with a greater CUAL decrease in the higher-dose group. Patients receiving teriflunomide in the original study had no further decrease in CUALs during this extension study. ${ }^{50}$ Relapse rates ( 0.4 relapses/year) and the proportion of patients without relapse during the study (54\%) were similar in both groups at the end of 144 weeks of follow-up. ${ }^{51}$

Confirming the long-term efficacy, a recent report on safety and efficacy outcomes at 8.5 years under teriflunomide for 85 patients from the initial extension study showed that ARRs remained low while a minimal disability progression was observed. A dose-dependent benefit with teriflunomide $14 \mathrm{mg}$ was noticed for several MRI parameters. The authors concluded that the overall safety profile of teriflunomide was favorable for up to 8.5 years. ${ }^{52}$

TEMSO (Teriflunomide MS Oral; NCT00134563) was a broader Phase III study of teriflunomide, adopting clinical outcomes as primary endpoints in larger populations and 


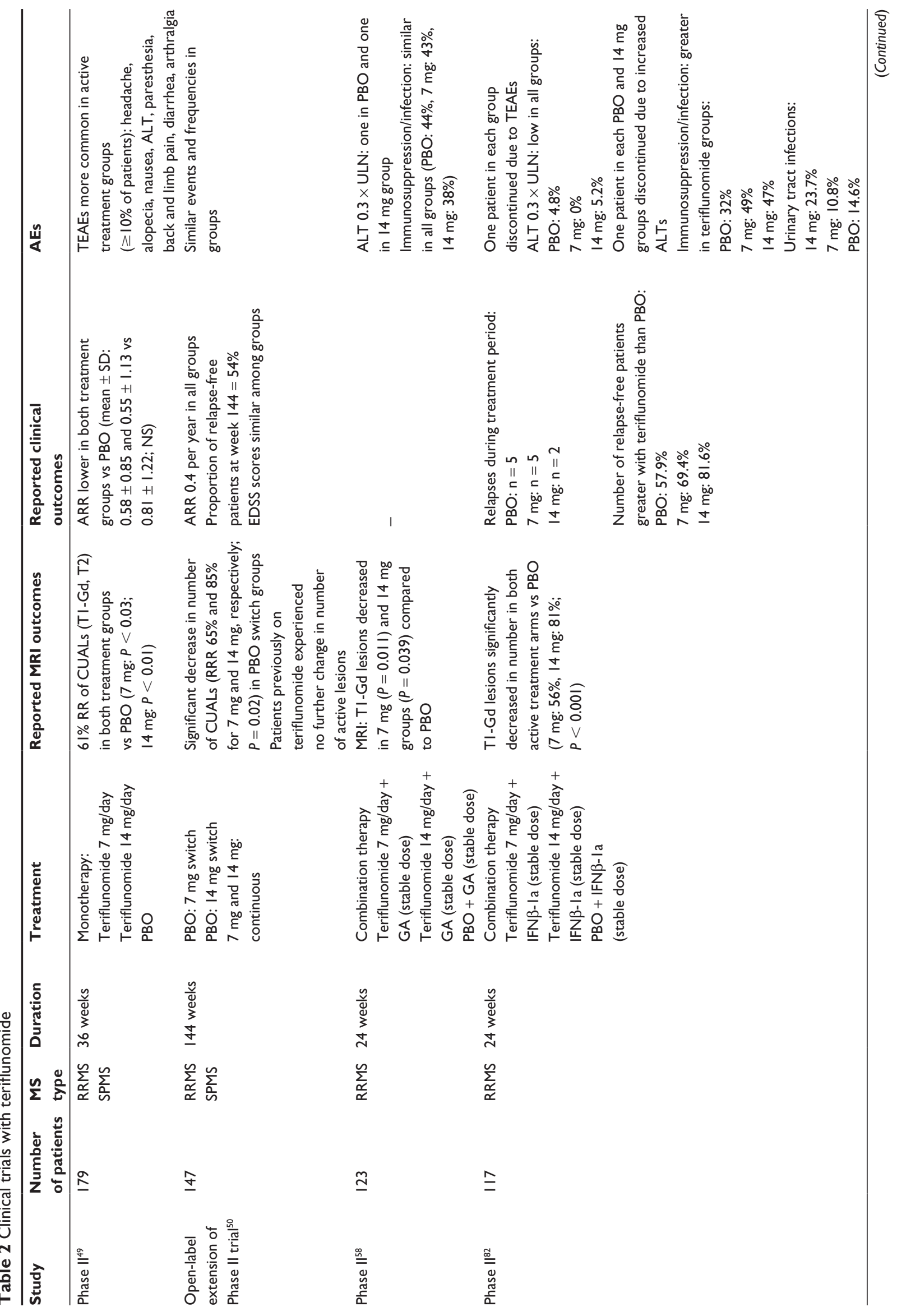




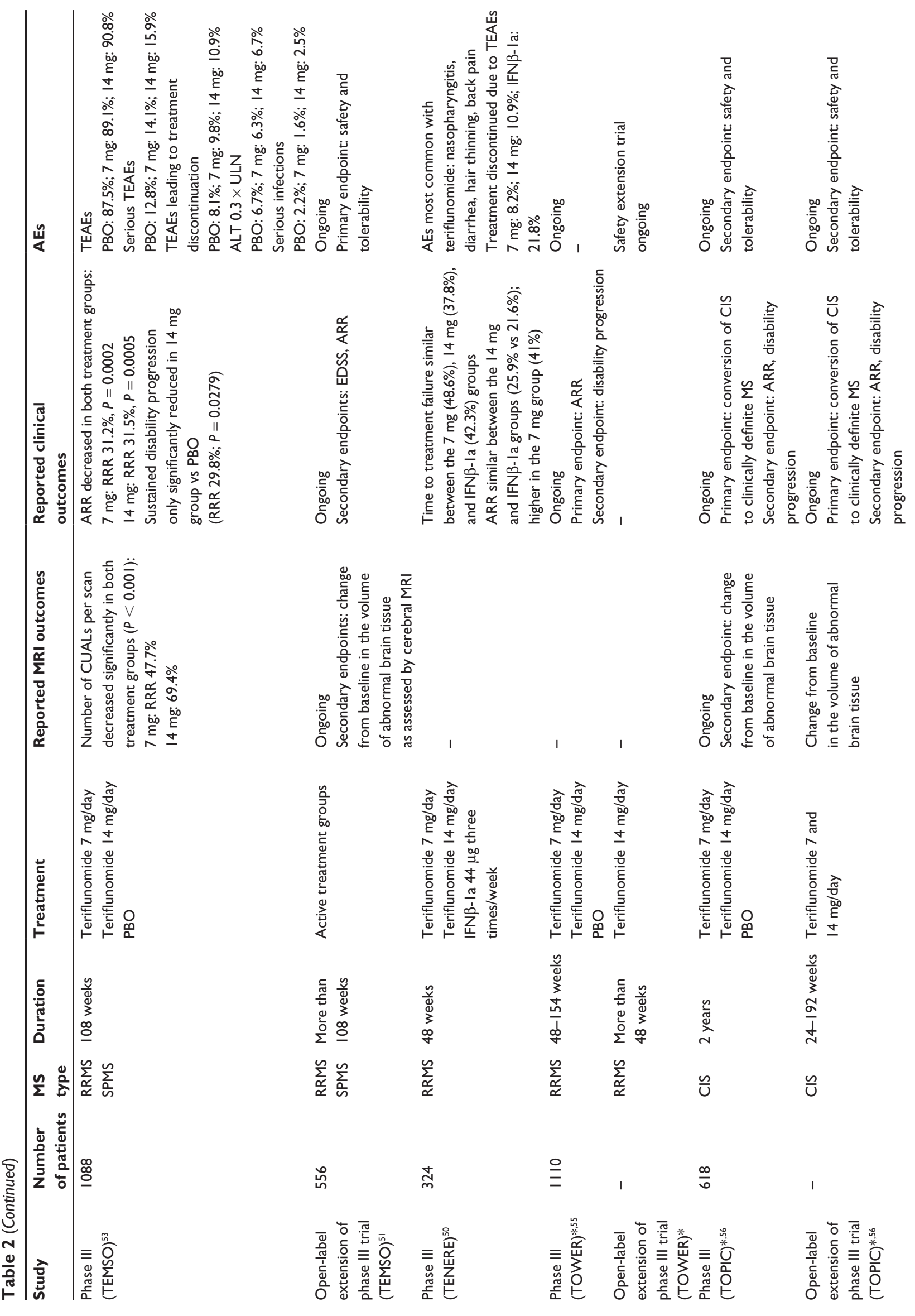




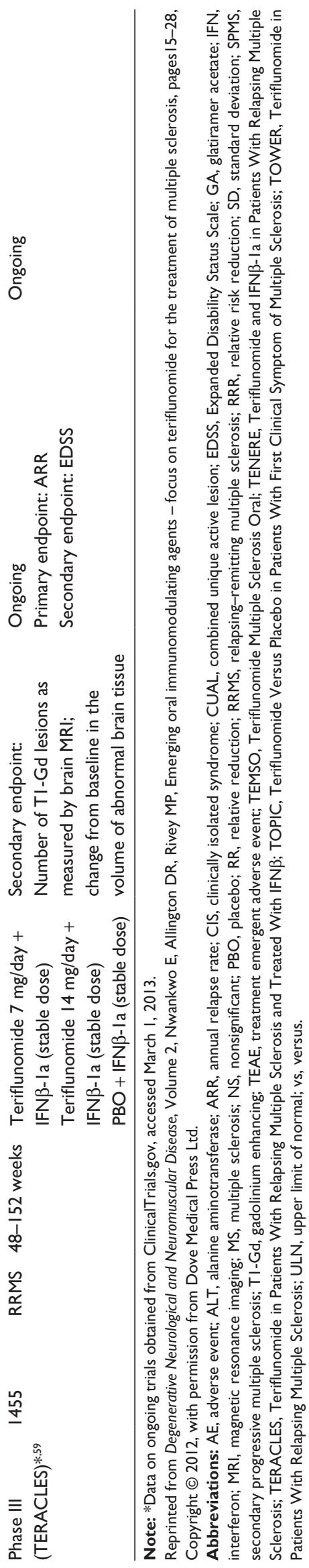

with a longer duration of treatment. ${ }^{53}$ Within a double-blind, parallel-group design, 1088 patients with either RRMS or progressive relapsing MS were randomized (1:1:1) to receive placebo, teriflunomide $7 \mathrm{mg}$ /day, or teriflunomide $14 \mathrm{mg} /$ day for 108 weeks..$^{53}$ To be included in the study, patients had to have a maximum EDSS score of 5.5 and either at least one relapse during the previous year or two relapses in the previous 2 years. The primary endpoint was the annualized relapse rate (ARR) while secondary endpoints included time to confirmed disability progression measured by EDSS and CUALs per MRI scan. Both doses of teriflunomide significantly decreased the ARR compared with placebo (0.370 ARR for $7 \mathrm{mg}$ /day; 0.369 for $14 \mathrm{mg}$ /day; 0.539 for placebo). ${ }^{53}$ The relative risk reductions were $31.2 \%(P=0.0002)$ and $31.5 \%(P=0.0005)$ for $7 \mathrm{mg}$ and $14 \mathrm{mg}$, respectively. Fewer patients receiving teriflunomide experienced disease progression $(21.7 \%$ for $7 \mathrm{mg} /$ day; $20.2 \%$ for $14 \mathrm{mg} /$ day; $27.3 \%$ for placebo). However, the relative risk for sustained progression was significantly reduced only in the $14 \mathrm{mg}$ group (29.8\% versus placebo; $P=0.0279) .{ }^{53}$ MRI scans were performed at baseline and at weeks 24, 48, 72, and 108. TEMSO MRI results confirmed those of the Phase II study. The number of CUALs per scan in the placebo, $7 \mathrm{mg}$, and $14 \mathrm{mg}$ groups was $2.463,1.288$, and 0.76 , respectively. This translates into a significant relative risk reduction of $47.7 \%$ and $69.4 \%$ for both drug doses $(P=0.001)$. A significant effect on sustained disability progression was observed only in the $14 \mathrm{mg} /$ day group.

Teriflunomide was well tolerated; the proportion of treatment emergent AEs were similar in all three groups. Discontinuation in the trial due to treatment emergent AEs occurred at similar rates in all groups and $73.2 \%$ of patients completed study treatment. ${ }^{53}$ Importantly, post hoc analyses showed that teriflunomide had an impact also on ARR leading to hospitalization, which was significantly reduced (36\% with $7 \mathrm{mg}, P=0.015 ; 59 \%$ with $14 \mathrm{mg}, P<0.0001$ ), and the annualized rate of emergency medical facility visits for the $14 \mathrm{mg}$ treatment group $(42 \%, P=0.004)$ versus placebo. ${ }^{53}$

Prespecified subgroup analyses from the TEMSO trial have recently been published. ${ }^{54}$ The objective of these preplanned analyses was to determine whether the effects of both doses of the drug on relapse rate and disability progression in the TEMSO study were demonstrated consistently in a range of prespecified patient subgroups related to demographic and disease characteristics at baseline. ${ }^{54}$ The analysis concluded that reductions in ARR and disability progression were consistently in favor of teriflunomide, with no treatmentby-subgroup interaction test reaching statistical significance. 
The effects were homogeneous across all baseline demographics, clinical, and MRI disease characteristics of all the prospectively defined subgroups in the TEMSO study population. $^{54}$

The extension of the TEMSO study offered new information on clinical and MRI outcomes 5 years after initial randomization. ${ }^{51}$ The 742 patients who completed the core study entered the long-term, double-blind extension, with those originally allocated to placebo being re-randomized to teriflunomide ( $7 \mathrm{mg}$ or $14 \mathrm{mg}$ ). Five years after randomization in the TEMSO study, taking into account the core study and extension, the risk of 12-week sustained disability progression was numerically lower in patients initially treated with teriflunomide compared with patients initially on placebo ( 0.371 in the $7 \mathrm{mg} / 7 \mathrm{mg}$ group compared with 0.420 in the placebo/7 mg group and 0.375 in the $14 \mathrm{mg} / 14 \mathrm{mg}$ group compared with 0.418 in the placebo/14 mg group). ${ }^{51}$ ARR during the extension period remained low $(0.251$, $0.234,0.182$, and 0.206 for placebo/ $7 \mathrm{mg}, 7 \mathrm{mg} / 7 \mathrm{mg}$, placebo/14 mg, and $14 \mathrm{mg} / 14 \mathrm{mg}$ groups, respectively). Changes from baseline in total MRI lesion volume (burden of disease) were numerically lower in the $7 \mathrm{mg} / 7 \mathrm{mg}$ group compared with the placebo/7 $\mathrm{mg}$ group and were also lower in the $14 \mathrm{mg} / 14 \mathrm{mg}$ group compared with the placebo/14 mg group. Both doses of teriflunomide were well tolerated and had favorable safety over the course of the extension, consistent with observations in the core TEMSO study. ${ }^{51}$ In summary, the beneficial effects of teriflunomide on clinical and MRI endpoints reported in TEMSO were maintained in the 5-year extension study. ${ }^{51}$ Numerically greater improvements were observed in patients who received teriflunomide throughout the core study and extension compared with those initially assigned to placebo. ${ }^{51}$

TOWER (Teriflunomide in Patients With Relapsing MS; NCT00751881) was the second large Phase III study of teriflunomide monotherapy, also evaluating the $7 \mathrm{mg}$ and $14 \mathrm{mg}$ daily doses of the active drug versus placebo. ${ }^{55}$ In this double-blind, parallel-group trial, 1169 RRMS patients were randomized. The inclusion criteria included a maximum EDSS score of 5.5 at screening, and at least one or two relapses in the 12 or 24 months prior to randomization, respectively. The study had variable treatment duration with a common end at 48 weeks after the last patient was randomized. The primary endpoint was again the ARR, while the key secondary endpoint was 12 -week sustained disability progression. Patients treated with $14 \mathrm{mg}$ had a $36.3 \%$ reduction in ARR versus placebo $(P<0.0001)$ and $31.5 \%$ reduced risk of 12 -week sustained disability progression $(P=0.0442)$.
Patients treated with $7 \mathrm{mg}$ had a $22.3 \%$ reduction in ARR versus placebo $(P=0.02)$, but there was no significant effect of $7 \mathrm{mg}$ on disability progression. Both doses were generally well tolerated with similar and manageable safety profiles. ${ }^{55}$ Commonly reported treatment emergent AEs with higher frequency on teriflunomide included headache, alanine aminotransferase elevations, hair thinning, diarrhea, nausea, and neutropenia. There were four deaths (placebo: respiratory infection; teriflunomide: motor vehicle accident, suicide, sepsis). ${ }^{55}$ The study showed, therefore, that teriflunomide significantly reduced ARR and, at the higher dose, disability progression. The results confirmed those of TEMSO, further supporting the potential value of the $14 \mathrm{mg}$ dose for patients with RRMS. ${ }^{55}$

The above trials have shown that teriflunomide is effective and safe in monotherapy. However, other points of interest such as how effective teriflunomide is in early RRMS or in conjunction with approved DMTs were addressed in other trials. Tackling the first issue, TOPIC (Teriflunomide Versus Placebo in Patients With First Clinical Symptom of MS; NCT00622700) is a randomized, double-blind, placebocontrolled Phase III study that will investigate the efficacy and safety of a 2 year-treatment with teriflunomide $7 \mathrm{mg} /$ day and $14 \mathrm{mg}$ /day versus placebo in patients with a first clinical episode suggestive of MS (clinically isolated syndrome) in the previous 90 days to inclusion. ${ }^{56}$ The primary endpoint in the trial will be the conversion to clinically definite MS and its termination date will be mid-2013.

Teriflunomide was also studied as adjunctive therapy with either IFN $\beta$ or GA in two randomized, doubleblinded, placebo-controlled Phase II trials. In the first study, 116 patients with RRMS under a stable dose of IFN $\beta$ for at least 26 weeks before screening were randomized to teriflunomide ( $7 \mathrm{mg}$ or $14 \mathrm{mg}$ ) or placebo for 6 months. ${ }^{57}$ Additional inclusion criteria were age $18-55$ years, a maximum EDSS score of 5.5, clinically stable condition for 4 weeks, and lack of relapses for 8 weeks prestudy ${ }^{57}$ The number and volume of enhancing lesions were reduced in both teriflunomide groups versus placebo ( $7 \mathrm{mg}$ : $56 \%$ and $14 \mathrm{mg}: 81 \% ; P<0.001)$ and a greater proportion of patients remained free of enhancing lesions during the treatment (placebo: $57.9 \%$, $7 \mathrm{mg}: 69.4 \%$, and $14 \mathrm{mg}: 81.6 \%) .{ }^{57}$ Of the 116 RRMS patients that were initially randomized to treatment for 6 months, 86 continued for a further 6 months (placebo: 31; 7 mg: 28; 14 mg: 27 patients). Evaluations included treatment emergent AEs, laboratory data, and brain MRI. In both teriflunomide arms, enhancing lesions were reduced, with relative risk reductions of $84.6 \%(P=0.0005)$ and 
$82.8 \%(P<0.0001)$ in $7 \mathrm{mg}$ and $14 \mathrm{mg}$ groups, respectively, versus placebo. Enhancing lesion volume was reduced by $46 \%$ for $7 \mathrm{mg}(P=0.059)$ and $66 \%$ for $14 \mathrm{mg}(P=0.123) .{ }^{57}$ A trend toward dose-dependent reduction in ARR was also noted (RRRs $32.6 \%, P=0.4$ and $57.9 \%, P=0.1005$ for $7 \mathrm{mg}$ and $14 \mathrm{mg}$, respectively). The authors concluded that the addition of teriflunomide to stable-dosed IFN $\beta$ significantly improved disease control evaluated by MRI activity beyond IFN $\beta$ alone, with a trend to a reduction in clinical relapse, and good safety and tolerability. ${ }^{57}$

A similar design was used for the Phase II study evaluating teriflunomide added to a stable dose of GA. ${ }^{58} \mathrm{~A}$ total of 123 patients with relapsing MS already receiving GA were randomized to once-daily $7 \mathrm{mg}$ or $14 \mathrm{mg}$ teriflunomide therapy or placebo. Again, the EDSS at screening had to be less than or equal to 5.5, the GA dose stable for at least 26 weeks prior to the study, and patients should have been clinically stable for 4 weeks prior to randomization and without relapses in the preceding 60 days prior to randomization. ${ }^{58}$ Compared to placebo, the number and volume of gadolinium-enhancing lesions were reduced in the $7 \mathrm{mg}$ group $(P=0.011)$ and in the $14 \mathrm{mg}$ group $(P=0.039)$. Overall, the addition of teriflunomide to GA improved disease control compared with GA therapy alone. ${ }^{58}$

Currently, a Phase III trial (TERACLES, Teriflunomide in Patients With Relapsing MS and Treated With IFN $\beta$; NCT01252355) studying the effects of teriflunomide as an add-on in RRMS patients treated with IFN $\beta$ is currently ongoing. ${ }^{59}$ Patients should have been on a stable dose of IFN $\beta$ for at least 6 months prior to screening and have disease activity (clinical relapse or MRI enhancing lesions) in the 12 months prior to randomization and after the first 3 months of IFN $\beta$ treatment. ${ }^{59}$ The primary objective of the trial is to assess the effect of teriflunomide in comparison to placebo on ARR in RRMS patients treated with IFN $\beta$. Secondary objectives are disease activity as measured by MRI, disability progression, safety, and tolerability as addon therapy; pharmacokinetics of teriflunomide; associations between variations in genes and clinical outcomes; fatigue and health-related quality of life; and measures of health economics (hospitalization due to relapse, including the length of stay and any admission to the intensive care unit).

Recently, the results of the first Phase III trial studying teriflunomide compared to a first-line DMT have been published..$^{60}$ TENERE (Teriflunomide and IFN $\beta$ - 1 a in Patients With Relapsing MS; NCT00883337) was a multicenter, randomized, parallel-group, rater-blinded study comparing the effectiveness and safety of teriflunomide and subcutaneous
IFN $\beta$-1a in patients with RRMS with a maximum EDSS score of 5.5 at baseline.$^{60}$ The patients $(n=324)$ were randomized to receive once-daily teriflunomide ( $7 \mathrm{mg}$ or $14 \mathrm{mg}$ ) or IFN $\beta$-1a (albumin-free formulation, three times weekly). The study had a fixed end; the approximate range of treatment duration for completers was 48-114 weeks. The primary endpoint was time to failure - defined as the first occurrence of confirmed relapse or permanent treatment discontinuation for any reason, whichever came first. ${ }^{60}$ Secondary endpoints included ARR, Fatigue Impact Scale score, and Treatment Satisfaction Questionnaire for Medication (TSQM) score. There was no statistical superiority for the primary endpoint when comparing the two teriflunomide groups with IFN $\beta$ - $1 \mathrm{a}$. The proportion of patients with failure was $48.6 \%, 37.8 \%$, and $42.3 \%$ for teriflunomide $7 \mathrm{mg}, 14 \mathrm{mg}$, and IFN $\beta$-1a respectively. The rate of permanent treatment discontinuation was lower in both teriflunomide groups than in the IFN $\beta$-1a group $(18.3 \%$, $19.8 \%$, and $28.8 \%$ ). No difference was detected in the adjusted ARRs between the teriflunomide $14 \mathrm{mg}$ and IFN $\beta$-1a groups ( 0.259 and 0.216 , respectively), but the rate was higher in the teriflunomide $7 \mathrm{mg}$ group $(0.410) .{ }^{60}$ Patients receiving either dose of teriflunomide reported a higher least-squares mean TSQM global satisfaction score, indicating better satisfaction than when treated with IFN $\beta-1 \mathrm{a} .{ }^{60}$ Both teriflunomide doses were well tolerated, with no unexpected safety signal identified. The authors concluded that although no statistical superiority was observed when comparing the two teriflunomide groups and IFN $\beta$-1a on the primary composite endpoint the rate of permanent, treatment discontinuation was lower in both teriflunomide groups than in the IFN $\beta$-1a group, thus making teriflunomide a candidate for first-line treatment in RRMS. $^{60}$

\section{Safety profile for teriflunomide}

Safety data and postmarketing AEs of leflunomide, now licensed for use in rheumatoid arthritis for more than a decade, are useful in defining the safety profile for teriflunomide. ${ }^{61}$ Leflunomide may cause liver damage; liver function tests are required prior to initiating therapy, then monthly for the first 6 months of treatment, and then every 6-8 weeks thereafter. ${ }^{36}$ Three cases of progressive multifocal leukoencephalopathy have been reported (two cases in patients with rheumatoid arthritis and one in a patient with systemic lupus erythematosus), two of whom received immunosuppressive drugs prior to leflunomide. ${ }^{62-64}$ However, no data exist that links teriflunomide use with progressive multifocal leukoencephalopathy. The occurrence of interstitial lung disease has been reported in rheumatoid 
arthritis patients being treated with leflunomide who have preexisting pulmonary conditions or are on premedication with methotrexate. ${ }^{65}$ In animal studies, leflunomide demonstrated a degree of reproductive toxicity, although a study of 64 pregnancies in women exposed to leflunomide observed no significant differences in the overall rate of structural birth defects compared to nonexposed pregnancies. ${ }^{66}$ However, in practice it is recommended that women of childbearing age under leflunomide utilize effective methods of contraception. ${ }^{67}$

The place of teriflunomide in MS therapy is strongly dependent on the safety and tolerability characteristics. Here, some of the issues regarding the biological, somatic, and teratogenic side effects of the drug will be briefly reviewed. As mentioned earlier, in teriflunomide trials AEs were distributed equally across all treatment and placebo groups (Table 3). Common adverse effects of teriflunomide include gastrointestinal symptoms (diarrhea, dyspepsia, nausea, vomiting, abdominal pain, and oral ulcers), increased levels of liver enzymes, skin rashes, weight loss, hair thinning, infections, and hypertension. ${ }^{53}$

In the Phase II trial of teriflunomide as monotherapy, despite the decrease in leukocytes seen in the active drug groups, infection rates were similar among drug and placebo groups and there were no discontinuations of therapy owing to leukopenia. ${ }^{49}$ However, a higher rate of infections in treated patients was seen when teriflunomide was combined with IFN $\beta$, but not in combination therapy with GA. ${ }^{33}$ In the TEMSO study, mean reductions in lymphocyte and neutrophil counts were small $(\leq 15 \%)$ and reversible after treatment discontinuation, or even on treatment. ${ }^{68}$ Overall, no other clinically significant complications to blood cytopenias were reported. ${ }^{68}$

In clinical trials, teriflunomide does appear to elevate alanine aminotransferase to a greater degree than placebo. However, in both the Phase II trial and TEMSO, the clinically

Table 3 Most common adverse events and their incidence (\%) in Phase II and Phase III trials with teriflunomide ${ }^{49-51}$

\begin{tabular}{lc}
\hline Adverse event & Incidence \\
\hline Alanine aminotransferase increase & $12 \%-14.2 \%$ \\
Headache & $19 \%-25 \%$ \\
Nasopharyngitis & $21 \%-26 \%$ \\
Diarrhea & $8 \%-17.9 \%$ \\
Alopecia & $12 \%-15 \%$ \\
Fatigue & $10 \%-14.5 \%$ \\
Nausea & $9 \%-13.7 \%$ \\
Urinary tract infection & $7.3 \%-11 \%$ \\
\hline Reprinted from Degenerative Neurological and Neuromuscular Disease, Volume 2, \\
Nwankwo E,Allington DR, Rivey MP, Emerging oral immunomodulating agents - focus \\
on teriflunomide for the treatment of multiple sclerosis, pages I -28, Copyright C \\
2012, with permission from Dove Medical Press Ltd.
\end{tabular}

significant elevations in hepatic transaminases were similar between placebo and treatment groups. ${ }^{49,53}$

Discontinuation rates in the TEMSO trial were $25 \%$ and $27 \%$ in the treatment group (for $7 \mathrm{mg}$ and $14 \mathrm{mg}$, respectively) and $29 \%$ in the placebo arm. The incidence of AEs was considered to be similar across the groups in the TEMSO study. Neither serious AEs (12.8\% versus $14.1 \%$ ) nor serious AEs leading to treatment discontinuation (8.1\% versus $9.8 \%$ ) were found to be significantly different between the tested doses of teriflunomide. ${ }^{53}$

Recent data on cessation of leflunomide in patients with rheumatoid arthritis suggest that differences in genes associated with the metabolism, clearance, and efficacy of leflunomide may play a role. ${ }^{69}$ In particular, the CYP2C19 phenotype was associated with cessation due to toxicity. Since CYP2C19 intermediate and poor metabolizers have lower teriflunomide concentrations, it was suggested that those patients were having a poor risk/benefit ratio when using the drug. ${ }^{69}$

The current approval for Aubagio contains a boxed warning to alert prescribers and patients to the risk of birth defects. Therefore, the drug is labeled as Pregnancy Category X, which means women of childbearing age must have a negative pregnancy test before starting the drug and use effective birth control during treatment. Study data showed that oral contraceptives maintained their efficacy with concurrent teriflunomide coadministration and didn't affect the drug's pharmacokinetics. ${ }^{33}$ As with leflunomide, women wishing to become pregnant should undergo a washout period with either cholestyramine or activated charcoal after stopping treatment with teriflunomide. ${ }^{33}$ If a pregnancy is planned, plasma levels of teriflunomide have to be below $0.02 \mathrm{mg} / \mathrm{L}$ in two separate tests 14 days apart. In the absence of washout procedure, due to the pharmacological profile of teriflunomide and the individual variations in drug clearance, it may take up to 2 years to reach those plasma levels. ${ }^{49}$

Pregnancy outcomes from the teriflunomide clinical development program were reported recently. ${ }^{70}$ The data were extracted from a retrospective analysis of seven teriflunomide clinical trials and included a total of 65 pregnancies, 43 of which were under teriflunomide. Upon learning of her pregnancy, the patient was instructed to discontinue the drug and go through an elimination procedure (cholestyramine or activated charcoal). The reported outcomes of the 43 pregnancies in teriflunomide-treated patients were: induced abortion ( $\mathrm{n}=20)$; spontaneous abortion $(\mathrm{n}=8)$; healthy newborn $(n=12)$; ongoing pregnancy $(n=2)$; and outcome pending in one case. ${ }^{70}$ No structural or functional deficits were reported 
in newborns with prenatal teriflunomide exposure following drug elimination. More prospective data are needed with respect to pregnancy outcomes and teriflunomide. ${ }^{70}$

Other undesirable effects have been reported in clinical studies using teriflunomide. In the pooled placebo-controlled trials, hair loss or thinning was more common with teriflunomide than with placebo, but in the majority of patients it was mild (76\%) and recovered without sequelae (85\%). ${ }^{71}$ The risk of hair loss and thinning was highest during the first 6 months of treatment, and overall less than $1 \%$ of patients discontinued treatment. Most cases resolved spontaneously without complication and without the need for hair loss treatment while the patient remained on teriflunomide. ${ }^{71}$

\section{Place of teriflunomide in MS therapy}

The development of oral therapies in MS presents not only opportunities and options, but also challenges. Oral agents as effective as, or more effective than the currently available injectable therapies would be a welcome advance in MS therapy. However, efficacy, safety, and tolerability are important in determining the new MS therapeutic armamentarium (Table 4). The impact of new drugs could finally translate into a better quality of life for the patient by both reducing (ideally eliminating) disease activity and providing a better patient satisfaction. The ease of administration would be an important point in favor of oral drugs, since up to $90 \%$ of MS patients using subcutaneous formulations of IFN $\beta$ and up to $33 \%$ for those using an intramuscular formulation experience some form of localized injection-site reaction. ${ }^{72}$ The use of an oral drug such as teriflunomide may improve adherence and reduce restrictions on lifestyle.

It is still to be determined how the newer drugs should be used relative to the time-tested injectable DMTs, how DMTs sequence should be determined, whether drugs should be used in combination, and how benefit/risk ratios for individual drugs will be compared in different MS populations. $^{73}$

Teriflunomide has a definite place within the increasing number of options for MS drugs. Efficacy, safety, and patient perspectives versus other oral therapies will determine its use. A survey fielded in March 2012 including 299 RRMS patients treated with first-line DMTs in the US showed that MS patients rate their current DMTs higher compared to neurologists but would expect new DMTs to be more convenient, safe, and tolerable. ${ }^{74,75}$

The extensive clinical development program for teriflunomide constitutes one of the widest programs of any of the new oral DMTs. Since the efficacy of teriflunomide is comparable to IFN $\beta$ and GA, patient-focused perspectives such as quality of life, patient satisfaction, adherence, and uptake would be crucial when choosing between the drug classes.

Once-daily teriflunomide is safe and well tolerated and its morbidity appears low. Data from the TEMSO trial showed that teriflunomide had the same impact as placebo on a utility score derived via a standardized health-related quality of life questionnaire administered during the study. This means that the drug was well-tolerated and displayed a favorable safety profile during the trial. ${ }^{76}$

Table 4 Oral drugs for relapsing-remitting multiple sclerosis

\begin{tabular}{|c|c|c|c|c|c|c|}
\hline Compound & $\begin{array}{l}\text { Mechanism } \\
\text { of action }\end{array}$ & Major trials & ARR RR & $\begin{array}{l}\text { MRI } \\
\text { lesions RR }\end{array}$ & $\begin{array}{l}\text { Dosing } \\
\text { regimen }\end{array}$ & Common AEs \\
\hline Teriflunomide & $\begin{array}{l}\text { Lymphocyte } \\
\text { antiproliferation }\end{array}$ & $\begin{array}{l}\text { TEMSO, TENERE } \\
\text { TOPIC, TERACLES }\end{array}$ & $>30 \%$ & CUALs $60 \%$ & Once daily & $\begin{array}{l}\text { 个LFTs, neutropenia, nasopharyngitis, } \\
\text { alopecia, nausea, paresthesia, diarrhea, } \\
\text { arthralgia, back and limb pain }\end{array}$ \\
\hline Fingolimod & $\begin{array}{l}\text { Lymphocyte } \\
\text { sequestration }\end{array}$ & $\begin{array}{l}\text { FREEDOMS } \\
\text { TRANSFORMS }\end{array}$ & $>50 \%$ & $\begin{array}{l}\text { Gd+ } \\
\text { lesions } 60 \%\end{array}$ & Once daily & $\begin{array}{l}\text { Lymphocytopenia, serious viral } \\
\text { infections, } \uparrow \text { LFTs, bradycardia, } \\
\text { AV block, macular edema, cancers }\end{array}$ \\
\hline Laquinimod & ThI toTh2 shift & $\begin{array}{l}\text { ALLEGRO, } \\
\text { BRAVO }\end{array}$ & $>20 \%$ & CUALs 40\% & Once daily & $\begin{array}{l}\text { 个LFTs, chest pain, back pain, } \\
\text { abdominal pain, viral infections, } \\
\text { menometrorrhagia with myofibroma, } \\
\text { exacerbation of preexisting glaucoma }\end{array}$ \\
\hline$B G \mid 2$ & $\begin{array}{l}\text { Activation } \\
\text { of Nrf2 pathway }\end{array}$ & $\begin{array}{l}\text { DEFINE, } \\
\text { CONFIRM }\end{array}$ & $>51 \%$ & $\begin{array}{l}\text { Gd+ } \\
\text { lesions } \sim 70 \%\end{array}$ & $\begin{array}{l}\text { Three times } \\
\text { daily }\end{array}$ & $\begin{array}{l}\text { Flushing, headache, nausea, } \\
\text { nasopharyngitis, pruritus, } \uparrow \text { LFTs }\end{array}$ \\
\hline
\end{tabular}

Reprinted from Degenerative Neurological and Neuromuscular Disease, Volume 2, Nwankwo E, Allington DR, Rivey MP, Emerging oral immunomodulating agents - focus on teriflunomide for the treatment of multiple sclerosis, pages 15-28, Copyright (C) 20I2, with permission from Dove Medical Press Ltd.

Abbreviations: AE, adverse event; ALLEGRO, Assessment of Oral Laquinimod in Preventing Progression of Multiple Sclerosis; ARR, annual relapse rate; AV, atrioventricular; CONFIRM, Oral BGI2 Versus Copaxone in Relapsing-Remitting Multiple Sclerosis; CUAL, combined unique active lesion; DEFINE, Oral BGI2 Versus Placebo in RelapsingRemitting Multiple Sclerosis; FREEDOMS, Fingolimod in Patients With Relapsing-Remitting Multiple Sclerosis; Gd+, gadolinium positive; LFT, liver function test; MRI, magnetic resonance imaging; RR, relative reduction; TEMSO, Teriflunomide Multiple Sclerosis Oral; TENERE, Teriflunomide and Interferon- $\beta$-Ia in Patients With Relapsing Multiple Sclerosis; TERACLES, Teriflunomide in Patients With Relapsing Multiple Sclerosis and Treated With Interferon- $\beta$; TOPIC, Teriflunomide Versus Placebo in Patients With First Clinical Symptom of Multiple Sclerosis; TRANSFORMS, Fingolimod in Patients With Relapsing-Remitting Multiple Sclerosis With Optional Extension Phase. 
In the TENERE study, the effects on patient satisfaction were compared between teriflunomide and subcutaneous IFN $\beta .{ }^{77}$ Patients receiving any of the doses of teriflunomide reported higher TSQM scores (higher score indicating greater satisfaction) for effectiveness ( $7 \mathrm{mg}, P=0.02$ and $14 \mathrm{mg}$, $P=0.27$ versus IFN $\beta)$, side effects $(P<0.0001$ for both doses versus IFN $\beta)$, and convenience $(P<0.0001$ for both doses versus IFN $\beta$ ) after 48 weeks of treatment. ${ }^{77}$ Moreover, the least-squares mean changes from baseline in the Fatigue Impact Scale total score at week 48 (positive change indicating a worsening) were in favor of teriflunomide. ${ }^{77}$ The combined least-squares mean and TSQM global satisfaction score at week 48 was again in favor of teriflunomide: 68.292 $(P=0.02$ versus IFN $\beta)$ for $7 \mathrm{mg} /$ day; $68.818(P=0.01)$ for $14 \mathrm{mg} /$ day; and 60.975 for IFN $\beta$. The authors concluded that teriflunomide-treated patients expressed greater satisfaction with treatment than those who received IFN $\beta .^{77}$

Convenience and patient preference may be the factors which may diminish the use of the injectable drugs as first-line treatment and lead to an increase in the use of oral compounds. The long-term safety profile of IFN $\beta$ and GA would argue for keeping those drugs as first-line DMTs; however, the liver toxicity of teriflunomide does not seem to be significantly different from fingolimod and IFN $\beta$ preparations. Teriflunomide would therefore be an option for patients who have used DMTs in the past and discontinued use because of side effects. Moreover, some patients with mild disease who are not using an injectable DMT might elect to use a convenient oral drug with a favorable safety profile such as teriflunomide. ${ }^{73}$ Also, teriflunomide might be an option for the proportion of patients already using injectable drugs who have breakthrough disease, are needle-phobic, or do not tolerate injectable compounds because of side effects.

For treatment-naive patients with RRMS, use of oral drugs such as teriflunomide as first-line treatment would correspond strongly with perceived safety. Finally, patients with clinically isolated syndrome would present a special challenge in the new era of emerging oral therapies. Teriflunomide could be one the drugs of choice if results from the TOPIC trial demonstrate its efficacy for this category of patients.

Future studies may clarify if teriflunomide is an option in patients with prolonged exposure to natalizumab who have John Cunningham virus antibodies, although the risk of disease activation after discontinuation of natalizumab is a concern. ${ }^{73}$

Teriflunomide seems to have (despite the lack of direct comparisons) lower effectiveness than the other oral compounds. Fingolimod and BG12 reduce relapses versus placebo by $54 \%$ and $53 \%$, respectively. ${ }^{8,14}$ Nevertheless, teriflunomide is easier to use than fingolimod, since there is no need for first-dose monitoring, no risk of macular edema or cardiac complications, and the washout period for the drug is shorter than for fingolimod (45 days for the latter). Therefore, teriflunomide may turn out to be an additional choice for MS patients.

An important aspect of the safety profile of teriflunomide in comparison to other oral agents is the long follow-up in studies (currently up to 8.5 years), enough to spot the development of opportunistic infections. However, since teriflunomide interferes with T-cell function, the occurrence later in time and when used more extensively in broader populations of infectious events cannot be excluded. However, appropriate immune response to infectious triggers and vaccinations could be normal under teriflunomide. ${ }^{23}$ Nevertheless, in the case of an acute infectious event, teriflunomide can be washed out of the system relatively quickly, thereby allowing the immune system to react fully to the infectious aggression. Long-term followup in larger MS populations could provide data on the potential of opportunistic infections and other conditions that have been associated with leflunomide.

Defining the best responder profile to teriflunomide is a challenge for future studies. Individual genetic or clinical features might predict an optimal response to teriflunomide for a given patient at some stage of the disease. Careful follow-up and pharmacogenomic studies might prove helpful in identifying an ideal candidate for teriflunomide. ${ }^{73}$

Currently, taking into account the immune model of MS pathogenesis and its proposed mechanism of action, teriflunomide may be most effective between the early stage of the disease and the relapsing-remitting stage and early during the latter stage - at a time when immune processes and linked inflammatory activity may be controlled - and as an alternative to injectable treatments. ${ }^{78}$

The landscape of MS treatments is changing fast. With the approval of new therapies and as information and experience accumulates, dramatic changes in MS therapeutic management are expected in the next 3 years. The choice between DMTs in MS will certainly depend upon efficacy and safety, but also on cost. In the US, teriflunomide currently costs $\$ 45,000$ a year per patient, while Copaxone ${ }^{\circledR}$ costs $7 \%$ more, Avonex ${ }^{\circledR} 8 \%$ more, and Gilenya ${ }^{\circledR} 28 \%$ more. MS drugs are some of the most expensive therapies on the market and recent studies show that health gains MS patients get from their medications come at an extremely high cost. ${ }^{79}$ 
The role and place of oral teriflunomide in MS therapy will therefore depend upon, and be influenced by, the results of long-term safety studies in wider populations and of comparator trials; on strategies allowing comparisons of treatment effects in large observational databases, such as propensity score-based methods; and on the information about the management of patients treated with the drug. ${ }^{80,81}$

Nevertheless, the approval of teriflunomide as the second oral DMT in MS is a step forward to better care and therapy management of this disabling condition.

\section{Disclosure}

Dr Radu Tanasescu has received travel support for scientific meetings from Biogen Idec, Lundbeck, and Novartis. Dr Nikos Evangelou has received honoraria and advisory fees from Bayer Healthcare, Merck Serono, Novartis, and Biogen Idec as well as support for research activities from Novartis. Dr Cris S Constantinescu has received research support from Biogen Idec, TEVA, GlaxoSmithKline, GW Pharmaceuticals, Bayer Schering, Merck Serono, and Roche.

\section{References}

1. Compston A, Coles A. Multiple sclerosis. Lancet. 2008;372(9648): 1502-1517.

2. Stys PK, Zamponi GW, van Minnen J, Geurts JJ. Will the real multiple sclerosis please stand up? Nat Rev Neurosci. 2012;13(7):507-514.

3. Evangelou N. The only way to manage neurodegeneration in MS is to prevent it with effective anti-inflammatory therapy: yes. Mult Scler. 2012;18(12):1680-1681.

4. Polman CH, Reingold SC, Banwell B, et al. Diagnostic criteria for multiple sclerosis: 2010 revisions to the McDonald criteria. Ann Neurol. 2011;69(2):292-302.

5. Fox EJ, Rhoades RW. New treatments and treatment goals for patients with relapsing-remitting multiple sclerosis. Curr Opin Neurol. 2012; 25 Suppl:S11-S19.

6. Osterberg L, Blaschke T. Adherence to medication. $N$ Engl J Med. 2005;353(5):487-497.

7. Giovannoni G, Comi G, Cook S, et al. A placebo-controlled trial of oral cladribine for relapsing multiple sclerosis. $N \mathrm{Engl} \mathrm{J} \mathrm{Med}$. 2010;362(5):416-426.

8. Kappos L, Radue EM, O'Connor P, et al. A placebo-controlled trial of oral fingolimod in relapsing multiple sclerosis. $N$ Engl J Med. 2010;362:387-401.

9. Cohen JA, Barkhof F, Comi G, et al. Oral fingolimod or intramuscular interferon for relapsing multiple sclerosis. $N$ Engl J Med. 2010;362:402-415. Expert Opin Pharmacother. 2010;11(10): 1777-1781.

10. Kappos L, Radue EW, O'Connor P, et al. A placebo-controlled trial of oral fingolimod in relapsing multiple sclerosis. $N$ Engl J Med. 2010; 362(5):387-401.

11. Cohen JA, Barkhof F, Comi G, et al. Oral fingolimod or intramuscular interferon for relapsing multiple sclerosis. $N \mathrm{Engl} \mathrm{J} \mathrm{Med}$. 2010;362(5):402-415.

12. Bruck W, Zamvil SS. Laquinimod, a once-daily oral drug in development for the treatment of relapsing-remitting multiple sclerosis. Expert Rev Clin Pharmacol. 2012;5(3):245-256.

13. Comi G, Jeffery D, Kappos L, et al. Placebo-controlled trial of oral laquinimod for multiple sclerosis. N Engl J Med. 2012;366(11):1000-1009.
14. Limmroth V. Multiple sclerosis: oral BG12 for treatment of relapsingremitting MS. Nat Rev Neurol. 2013;9(1):8-10.

15. Gold R, Kappos L, Arnold DL, et al. Placebo-controlled phase 3 study of oral BG-12 for relapsing multiple sclerosis. $N$ Engl J Med. 2012;367(12):1098-1107.

16. Fox RJ, Miller DH, Phillips JT, et al. Placebo-controlled phase 3 study of oral BG-12 or glatiramer in multiple sclerosis. $N$ Engl J Med. 2012;367(12):1087-1097.

17. Gasperini C, Ruggieri S. Development of oral agent in the treatment of multiple sclerosis: how the first available oral therapy, fingolimod, will change therapeutic paradigm approach. Drug Des Devel Ther. 2012;6: 175-186.

18. Fontoura P, Garren H. Multiple sclerosis therapies: molecular mechanisms and future. Results Probl Cell Differ. 2010;51:259-285.

19. Chan EC, New LS. In vitro metabolism of leflunomide by mouse and human liver microsomes. Drug Metab Lett. 2007;1(4):299-305.

20. Herrmann ML, Schleyerbach R, Kirschbaum BJ. Leflunomide: an immunomodulatory drug for the treatment of rheumatoid arthritis and other autoimmune diseases. Immunopharmacology. 2000;47(2-3): 273-289.

21. Tallantyre E, Evangelou N, Constantinescu CS. Spotlight on teriflunomide. Int MS J. 2008;15(2):62-68.

22. Posevitz V, Chudyka D, Kurth F, Wiendl H. Teriflunomide suppresses antigen induced T-cell expansion in a TCR avidity dependent fashion. 28th Congress of the European Committee for Research and Treatment in Multiple Sclerosis (ECTRIMS); October 10-13, 2012; Lyon, France.

23. Bar-Or A, Freedman MS, Kremenchutzky M, et al. Effect of teriflunomide on immune responses to seasonal influenza vaccination in patients with relapsing multiple sclerosis: results from the TERIVA study. 28th Congress of the European Committee for Research and Treatment in Multiple Sclerosis (ECTRIMS); October 10-13, 2012; Lyon, France.

24. Korn T, Toyka K, Hartung HP, Jung S. Suppression of experimental autoimmune neuritis by leflunomide. Brain. 2001;124(Pt 9):1791-1802.

25. Korn T, Magnus T, Toyka K, Jung S. Modulation of effector cell functions in experimental autoimmune encephalomyelitis by leflunomide - mechanisms independent of pyrimidine depletion. J Leukoc Biol. 2004;76(5):950-960.

26. Zeyda M, Poglitsch M, Geyeregger R, et al. Disruption of the interaction of $\mathrm{T}$ cells with antigen-presenting cells by the active leflunomide metabolite teriflunomide: involvement of impaired integrin activation and immunologic synapse formation. Arthritis Rheum. 2005;52(9): 2730-2739.

27. Mattar T, Kochhar K, Bartlett R, Bremer EG, Finnegan A. Inhibition of the epidermal growth factor receptor tyrosine kinase activity by leflunomide. FEBS Lett. 1993;334(2):161-164.

28. Migita K, Miyashita T, Ishibashi H, et al. Suppressive effect of leflunomide metabolite (A77 1726) on metalloproteinase production in IL-1 $\beta$ stimulated rheumatoid synovial fibroblasts. Clin Exp Immunol. 2004;137(3):612-616.

29. Siemasko K, Chong AS, Jack HM, Gong H, Williams JW, Finnegan A. Inhibition of JAK 3 and STAT 6 tyrosine phosphorylation by the immunosuppressive drug leflunomide leads to a block in IgG1 production. J Immunol. 1998;160(4):1581-1588.

30. Xu X, Williams JW, Bremer EG, Finnegan A, Chong AS. Inhibition of protein tyrosine phosphorylation in T cells by a novel immunosuppressive agent, leflunomide. J Biol Chem. 1995;270(21):12398-12403.

31. Xu X, Williams JW, Gong H, Finnegan A, Chong AS. Two activities of the immunosuppressive metabolite of leflunomide, A77 1726. Inhibition of pyrimidine nucleotide synthesis and protein tyrosine phosphorylation. Biochem Pharmacol. 1996;52(4):527-534.

32. Hoskin DW, Taylor RM, Makrigiannis AP, James H, Lee TD. Dosedependent enhancing and inhibitory effects of A77 1726 (leflunomide) on cytotoxic T lymphocyte induction. Int J Immunopharmacol. 1998; 20(9):505-513.

33. Nwankwo E, Allington DR, Rivey MP. Emerging oral immunomodulating agents - focus on teriflunomide for the treatment of multiple sclerosis. Degener Neurol Neuromuscul Dis. 2012;2:15-28. 
34. Dimitrova P, Skapenko A, Herrmann ML, Schleyerbach R, Kalden JR, Schulze-Koops H. Restriction of de novo pyrimidine biosynthesis inhibits Th1 cell activation and promotes Th2 cell differentiation. J Immunol. 2002;169(6):3392-3399.

35. Deage V, Burger D, Dayer JM. Exposure of T lymphocytes to leflunomide but not to dexamethasone favors the production by monocytic cells of interleukin-1 receptor antagonist and the tissue-inhibitor of metalloproteinases- 1 over that of interleukin- $1 \beta$ and metalloproteinases. Eur Cytokine Netw. 1998;9(4):663-668.

36. Claussen MC, Korn T. Immune mechanisms of new therapeutic strategies in MS: teriflunomide. Clin Immunol. 2012;142(1):49-56.

37. Miljkovic D, Samardzic T, Mostarica Stojkovic M, Stosic-Grujicic S, Popadic D, Trajkovic V. Leflunomide inhibits activation of inducible nitric oxide synthase in rat astrocytes. Brain Res. 2001;889(1-2):331-338.

38. Hamilton LC, Vojnovic I, Warner TD. A771726, the active metabolite of leflunomide, directly inhibits the activity of cyclo-oxygenase-2 in vitro and in vivo in a substrate-sensitive manner. $\mathrm{Br} J$ Pharmacol. 1999;127(7):1589-1596.

39. Jankovic V, Samardzic T, Stosic-Grujicic S, Popadic D, Trajkovic V. Cell-specific inhibition of inducible nitric oxide synthase activation by leflunomide. Cell Immunol. 2000;199(2):73-80.

40. Li L, Liu J, Zhang D, Jones C. Teriflunomide treatment of human monocyte-derived dendritic cells in vitro does not impair their maturation or ability to induce allogeneic T-cell responses. 28th Congress of the European Committee for Research and Treatment in Multiple Sclerosis (ECTRIMS); October 10-13, 2012; Lyon, France.

41. Bartlett RR, Dimitrijevic M, Mattar T, et al. Leflunomide (HWA 486), a novel immunomodulating compound for the treatment of autoimmune disorders and reactions leading to transplantation rejection. Agents Actions. 1991;32(1-2):10-21.

42. Munier-Lehmann H, Vidalain PO, Tangy F, Janin YL. On dihydroorotate dehydrogenases and their inhibitors and uses. $J$ Med Chem. March 20, 2013. [Epub ahead of print.]

43. LimsakunT, Menguy-Vacheron F. Pharmacokinetics of oral teriflunomide, a novel oral disease-modifying agent under investigation for the treatment of MS. Annual Meeting of the American Academy of Neurology (AAN); April 10-17, 2010; Toronto, ON, Canada.

44. Rozman B. Clinical pharmacokinetics of leflunomide. Clin Pharmacokinet. 2002;41(6):421-430.

45. Lim V, Pande I. Leflunomide can potentiate the anticoagulant effect of warfarin. BMJ. 2002;325(7376):1333.

46. Turpault S, Mair S, Meng Z, Hochet A, Menguy-Vacheron F. Effect of teriflunomide on the pharmacodynamic and pharmacokinetic profiles of warfarin in healthy male subjects. 28th Congress of the European Committee for Research and Treatment in Multiple Sclerosis (ECTRIMS); October 10-13, 2012; Lyon, France.

47. Bergner R, Peters L, Schmitt V, Loffler C. Leflunomide in dialysis patients with rheumatoid arthritis - a pharmacokinetic study. Clin Rheumatol. 2013;32(2):267-270.

48. Merrill JE, Hanak S, Pu SF, et al. Teriflunomide reduces behavioral, electrophysiological, and histopathological deficits in the Dark Agouti rat model of experimental autoimmune encephalomyelitis. $J$ Neurol. 2009;256(1):89-103.

49. O'Connor PW, Li D, Freedman MS, et al. A Phase II study of the safety and efficacy of teriflunomide in multiple sclerosis with relapses. Neurology. 2006;66(6):894-900.

50. O'Connor PW, Freedman MS, Bar-Or A, Rice GP, Confavreux C, Traboulsee A. Oral teriflunomide is effective and well tolerated in multiple sclerosis with relapses: results of an open-label 144-week extension study. 22nd Congress of the European Committee for the Treatment and Research in Multiple Sclerosis; September 27-30, 2006; Madrid, Spain.

51. O'Connor P, Wolinsky JS, Confavreux C, et al. Extension of a phase III trial (TEMSO) of oral teriflunomide in multiple sclerosis with relapses: clinical and MRI data 5 years after initial randomisation. Fifth Joint Triennial Congress of the European and Americas Committees for Treatment and Research in Multiple Sclerosis; October 19-22, 2011; Amsterdam, The Netherlands.
52. Confavreux C, Li DK, Freedman MS, et al. Long-term follow-up of a phase 2 study of oral teriflunomide in relapsing multiple sclerosis: safety and efficacy results up to 8.5 years. Mult Scler. 2012;18(9): $1278-1289$.

53. O'Connor P, Wolinsky JS, Confavreux C, et al. Randomized trial of oral teriflunomide for relapsing multiple sclerosis. $N$ Engl J Med. 2011;365(14):1293-1303

54. Miller AE, O'Connor P, Wolinsky JS, et al. Pre-specified subgroup analyses of a placebo-controlled phase III trial (TEMSO) of oral teriflunomide in relapsing multiple sclerosis. Mult Scler. 2012;18(11):1625-1632.

55. Kappos L, Comi G, Confavreux C, et al. The efficacy and safety of teriflunomide in patients with relapsing MS: results from TOWER, a phase III, placebo-controlled study. 28th Congress of the European Committee for Research and Treatment in Multiple Sclerosis (ECTRIMS); October 10-13, 2012; Lyon, France.

56. Sanofi. Phase III study with teriflunomide versus placebo in patients with first clinical symptom of multiple sclerosis (TOPIC). In: ClinicalTrials. gov [website on the Internet]. Bethesda, MD: US National Library of Medicine; 2008 [updated November 5, 2012]. Available from: http:// clinicaltrials.gov/show/NCT00622700. NLM identifier: NCT00622700. Accessed March 1, 2013.

57. Freedman MS, Wolinsky JS, Wamil B, et al. Teriflunomide added to interferon- $\beta$ in relapsing multiple sclerosis: a randomized phase II trial. Neurology. 2012;78(23):1877-1885.

58. Freedman M, Wolinsky JS, Frangin GA. Oral teriflunomide or placebo added to glatiramer acetate for 6 months in patients with relapsing multiple sclerosis: safety and efficacy results. 62nd Annual Meeting of the American Academy of Neurology (AAN); April 10-17, 2010; Toronto, ON, Canada.

59. Sanofi. Efficacy and safety of teriflunomide in patients with relapsing multiple sclerosis and treated with interferon- $\beta$ (TERACLES). In: ClinicalTrials.gov [website on the Internet]. Bethesda, MD: US National Library of Medicine; 2010 [updated February 21, 2013]. Available from: http://clinicaltrials.gov/show/NCT01252355. NLM identifier: NCT01252355. Accessed March 1, 2013.

60. Vermersch P, Czlonkowska A, Grimaldi L, et al. A multicenter, randomized, parallel-group, rater-blinded study comparing the effectiveness and safety of teriflunomide and subcutaneous interferon $\beta$-1a in patients with relapsing multiple sclerosis. Fourth Cooperative Meeting of CMSC and ACTRIMS; May 30-Jun 2, 2012; San Diego, CA, USA.

61. Alcorn N, Saunders S, Madhok R. Benefit-risk assessment of leflunomide: an appraisal of leflunomide in rheumatoid arthritis 10 years after licensing. Drug Saf. 2009;32(12):1123-1134.

62. Rahmlow M, Shuster EA, Dominik J, et al. Leflunomide-associated progressive multifocal leukoencephalopathy. Arch Neurol. 2008;65(11): $1538-1539$.

63. Clifford DB, Ances B, Costello C, et al. Rituximab-associated progressive multifocal leukoencephalopathy in rheumatoid arthritis. Arch Neurol. 2011;68(9):1156-1164.

64. Harris HE. Progressive multifocal leucoencephalopathy in a patient with systemic lupus erythematosus treated with rituximab. Rheumatology (Oxford). 2008;47(2):224-225.

65. Sawada T, Inokuma S, Sato T, et al. Leflunomide-induced interstitial lung disease: prevalence and risk factors in Japanese patients with rheumatoid arthritis. Rheumatology (Oxford). 2009;48(9):1069-1072.

66. Chambers CD, Johnson DL, Robinson LK, et al. Birth outcomes in women who have taken leflunomide during pregnancy. Arth Rheum. 2010;62(5):1494-1503.

67. Brent RL. Teratogen update: reproductive risks of leflunomide (Arava); a pyrimidine synthesis inhibitor: counseling women taking leflunomide before or during pregnancy and men taking leflunomide who are contemplating fathering a child. Teratology. 2001;63(2):106-112.

68. Comi G, Benzerdjeb H, Wang L, Truffinet P, O'Connor P. Effect of teriflunomide on lymphocyte and neutrophil levels in patients with relapsing multiple sclerosis: results from the TEMSO study. 28th Congress of the European Committee for Research and Treatment in Multiple Sclerosis (ECTRIMS); October 10-13, 2012; Lyon, France. 
69. Wiese MD, Schnabl M, O’Doherty C, et al. Polymorphisms in cytochrome P450 2C19 enzyme and cessation of leflunomide in patients with rheumatoid arthritis. Arthritis Res Ther. 2012;14(4):R163.

70. Kieseier B, Benamor M, Benzerdjeb H, Stuve O. Pregnancy outcomes from the teriflunomide clinical development programme: retrospective analysis of the teriflunomide clinical trial database. 28th Congress of the European Committee for Research and Treatment in Multiple Sclerosis (ECTRIMS); October 10-13, 2012; Lyon, France.

71. Freedman MS, Confavreux C, Comi G, et al. Hair thinning associated with teriflunomide therapy is manageable. Fourth Cooperative Meeting of CMSC and ACTRIMS; May 30-Jun 2, 2012; San Diego, CA, USA.

72. Balak DM, Hengstman GJ, Cakmak A, Thio HB. Cutaneous adverse events associated with disease-modifying treatment in multiple sclerosis: a systematic review. Mult Scler. 2012;18(12):1705-1717.

73. Killestein J, Rudick RA, Polman CH. Oral treatment for multiple sclerosis. Lancet Neurol. 2011;10(11):1026-1034.

74. BioTrends Research Group. TreatmentTrends ${ }^{\circledR}:$ Multiple Sclerosis (US) 2012. Exton, PA: BioTrends Research Group; 2012. Available from: http://bio-trends.com/Images---Files/Products-and-Services/Products/ TT-Report-Overviews/2011-Report-Overviews/TreatmentTrends/ TreatmentTrends-Multiple-Sclerosis-in-the-US-1-5-1.aspx. Accessed March 22, 2013.

75. BioTrends Research Group. PatientTrends ${ }^{\circledR}$ : Multiple Sclerosis (US) 2012. Exton, PA: BioTrends Research Group; 2012. Available from: http://bio-trends.com/Images---Files/Products-and-Services/Products/ TT-Report-Overviews/2011-Report-Overviews/PatientTrends/ PatientTrends-Multiple-Sclerosis-1-17-12.aspx. Accessed March 22, 2013.
76. O’Connor P, Briggs A, Carita P, Bego-Le-Bagousse G. Impact on healthrelated quality of life of teriflunomide treatment by estimating utilities in patients with relapsing multiple sclerosis: results from TEMSO post hoc analysis. Annual Meeting of the European Neurological Society (ENS); June 9-12, 2012; Prague, Czech Republic.

77. Vermersch P, Czlonkowska A, Grimaldi L, et al. Evaluation of patient satisfaction from the TENERE study: a comparison of teriflunomide and subcutaneous interferon $\beta$-1a in patients with relapsing multiple sclerosis. Annual Meeting of the European Neurological Society (ENS); June 9-12, 2012; Prague, Czech Republic.

78. Gold R, Wolinsky JS. Pathophysiology of multiple sclerosis and the place of teriflunomide. Acta Neurol Scand. 2011;124(2):75-84.

79. Noyes K, Bajorska A, Chappel A, et al. Cost-effectiveness of diseasemodifying therapy for multiple sclerosis: a population-based study. Neurology. 2011;77(4):355-363.

80. Trojano M, Pellegrini F, Paolicelli D, Fuiani A, Di Renzo V. Observational studies: propensity score analysis of non-randomized data. Int MS J. 2009;16(3):90-97.

81. He D, Xu Z, Dong S, et al. Teriflunomide for multiple sclerosis [review]. Cochrane Database Syst Rev. 2012;12:CD009882.

82. Freedman MS, Wolinsky JS, Byrnes WJ, et al. Oral teriflunomide or placebo added to interferon beta for months in patients with relapsing multiple sclerosis: safety and efficacy results. 25th Congress of the European Committee for Treatment and Research in Multiple Sclerosis (ECTRIMS); September 9-12, 2009; Dusseldorf, Germany.
Neuropsychiatric Disease and Treatment

\section{Publish your work in this journal}

Neuropsychiatric Disease and Treatment is an international, peerreviewed journal of clinical therapeutics and pharmacology focusing on concise rapid reporting of clinical or pre-clinical studies on a range of neuropsychiatric and neurological disorders. This journal is indexed on PubMed Central, the 'PsycINFO' database and CAS.

\section{Dovepress}

The manuscript management system is completely online and includes a very quick and fair peer-review system, which is all easy to use. Visit http://www.dovepress.com/testimonials.php to read real quotes from published authors. 